\title{
Ações voltadas a cobertura vacinal contra Febre Amarelaa partir de atividades prática de epidemiologia
}

\author{
Actions aimed at vaccine coverage against Yellow Fever from practical epidemiological activities \\ Acciones dirigidas a cobertura vacunal contra FiebreAmarilla a partir de actividadesprácticas de \\ epidemiología
}

Evelyn Franco e Silva $^{1 *}$, Francielle Oliveira ${ }^{1}$, Luiz Fernando Correa ${ }^{1}$, Mônica do Nascimento Oliveira ${ }^{1}$,
Paulo Sergio Coutinho ${ }^{1}$, Sebastião Jorge Cunha Gonçalves ${ }^{2}$

Como citar esse artigo. Silva, EF; Oliveira, F; Correa, LF; Oliveira, MN; Coutinho, PS; Gonçalves, SJC. Ações voltadas a cobertura vacinal contra Febre Amarela a partir de atividades prática de epidemiologia. Revista Pró-UniverSUS. 2019 Jan./Jun.; 10 (1): 110-118.

\section{Resumo}

O presente estudo trata sobre a aplicação de medidas de prevenção e controle da doença Febre Amarela. Tem por objetivo avaliar dados a partir da varredura e monitoramento vacinal realizado por acadêmicos de Enfermagem da Universidade de Vassouras RJ. Estudo quantitativo, realizado a partir de ações desenvolvidas no decorrer de uma atividade prática da Disciplina Epidemiologia Clínica e Enfermagem. Verificou-se cobertura vacinal de aproximadamente $176 \%$ da população estudada. Importante verificar a importância da varredura e monitoramento vacinal, o atendimento pelas equipes de vacinação que promovam a qualidade dos serviços prestados, o acolhimento e a adesão da população.

Palavras-chave: Febre amarela, Varredura, Monitoramento Vacinal

\begin{abstract}
The present study deals with the application of measures to prevent and control Yellow Fever disease. It aims to evaluate data from the vaccination scan and monitoring performed by Nursing academics of the University of Vassouras RJ. Quantitative study, carried out from actions developed during a practical activity of the Clinical Epidemiology and Nursing Discipline. Vaccination coverage of approximately $176 \%$ of the study population was verified. It is important to verify the importance of the vaccination scan and monitoring, the assistance by the vaccination teams that promote the quality of the services provided, the reception and the adhesion of the population.

Keywords: Yellow fever, sweep, vaccine monitoring.
\end{abstract}

\section{Resumen}

El presente estudio trata sobre la aplicación de medidas de prevención y control de la enfermedad Fiebre Amarilla. Tiene por objetivo evaluar datos a partir de la exploración y monitoreo vacunal realizado por académicos de Enfermería de la Universidad de Vassouras RJ. Estudio cuantitativo, realizado a partir de acciones desarrolladas en el transcurso de una actividad práctica de la Disciplina Epidemiología Clínica y Enfermería. Se verificó cobertura vacunal de aproximadamente el 176\% de la población estudiada. Es importante verificar la importancia de la exploración y monitoreo de la vacunación, la atención por los equipos de vacunación que promuevan la calidad de los servicios prestados, la acogida y la adhesión de la población.

Palabras clave: Fiebreamarilla, Exploración, Monitoreo Vacunal

2Enfermeira pela Universidade de Vassouras. RJ, Brasil. Email: francielleoliveira23@outlook.com ORCID: https://orcid.org/0000-0001-7034-5950

3 Enfermeiro pela Universidade de Vassouras. RJ, Brasil. Email: luiz.nandocorrea@gmail.com ORCID: https://orcid.org/0000-0002-7468-5052

4 Enfermeira pela Universidade de Vassouras. RJ, Brasil. Email: monicao79@hotmail.comORCID: https://orcid.org/0000-0002-7755-3389

5 Enfermeiro pela Universidade de Vassouras. RJ, Brasil. Email: pscoutinho30@hotmail.com ORCID: https://orcid.org/0000-0002-4957-8036

6Mestre. Professor do Curso de Enfermagem, Universidade de Vassouras. RJ, Brasil. Email: sjcunha@uol.com.br ORCID: https://orcid.org/0000-0002-4228-4641 


\section{Introdução}

A febre amarela (FA) é uma doença infecciosa aguda, febril, não contagiosa, de curta duração (no máximo de 12 dias) e de gravidade variável. É produzida por um arbovírus do gênero Flavivirus, família Flaviviridae. Apresenta dois ciclos epidemiológicos de acordo com o local de ocorrência e a espécie de vetor (mosquito transmissor): urbano e silvestre.

O Ministério da Saúde atualizou informativo técnico em 07 de fevereiro de 2018, as informações repassadas pelas secretarias estaduais de saúde sobre a situação da febre amarela no país. No período de monitoramento (de $1^{\circ}$ de julho/2017 a 6 de fevereiro de 2018), foram confirmados 353 casos de febre amarela no país, sendo que 98 vieram a óbito. Ao todo, foram notificados 1.286 casos de febre amarela suspeitos, sendo que 510 foram descartados e 423 permanecem em investigação, neste período. ${ }^{1}$

No ano passado, de julho de 2016, até 6 fevereiro de 2017, eram 509 casos de febre amarela confirmados e 159 óbitos confirmados. Os informes de febre amarela seguem, desde o ano passado, a sazonalidade da doença, que acontece, em sua maioria, no verão. ${ }^{1}$

Segundo dados do Ministério da Saúde, a região Sudeste registrou 764 casos confirmados, a maior parte. A vacinação foi reforçada com 27,8 milhões de doses extras em cinco estados: Minas Gerais, Rio de Janeiro, São Paulo, Espírito Santo e Bahia. Em São Paulo, 44 municípios passaram a ser áreas com recomendação permanente.

O surto de febre amarela no Brasil, apesar de atingir regiões próximas de zonas urbanas de estados como Rio de Janeiro e São Paulo, foi classificado como silvestre pelo governo brasileiro.

$\mathrm{Na}$ cidade de Vassouras, o primeiro caso confirmado foi em Fevereiro de 2018. A partir disto, estudantes de enfermagem da Universidade de Vassouras, resolveram realizar varredura de cobertura vacinal contra a febre amarela, assim como a realização de vacina na população ainda não imunizada.

O estudo tem por objetivo avaliar dados a partir da varredura e monitoramento vacinal realizado por acadêmicos de Enfermagem da Universidade de Vassouras.

\section{Material e métodos}

Trata-se de um trabalho quantitativo, realizado a partir de ações desenvolvidas no decorrer de uma atividade prática da Disciplina Epidemiologia Clínica e Enfermagem no mês de fevereiro de 2018. A estratégia inclui atividades práticas voltadas à duas (2) comunidades de Vassouras, RJ, nos bairros Matadouro e Conjunto Habitacional - Centro. Os alunos foram distribuídos em duplas, juntamente com um Agente Comunitário de Saúde das Micro áreas. Foram realizados a identificação dos domicílios, através do cadastro do e-sus 2018, número de pessoas residentes no domicílio, solicitação do comprovante vacinal de febre amarela. Considerando os vacinados e não vacinados que posteriormente foram vacinados em seus domicílios ou em sua Unidade Saúde da Família, a intensão era realizar a estratégia com aqueles que não foram vacinado.

Foi utilizado uma planilha do programa Excel para a consolidação das informações obtidas a partir no decorrer da estratégia.

\section{Resultados e discussão}

A febre amarela (FA) é uma doença infecciosa aguda, febril, não contagiosa, de curta duração (no máximo de 12 dias) e de gravidade variável. É produzida por um arbovírus do gênero Flavivirus, família Flaviviridae. Apresenta dois ciclos Epidemiológicos de acordo com o local de ocorrência e a espécie de vetor (mosquito transmissor): urbano e silvestre.

Do ponto de vista etiológico, clínico, imunológico e fisiopatológico, a doença é a mesma nos dois ciclos. No ciclo urbano, a doença é uma antroponose, não se reconhecendo reservatórios animais de importância epidemiológica. O Aedes aegypti é seu principal vetor, tanto na América do Sul como na África. No ciclo silvestre, a febre amarela é uma zoonose, transmitida, no continente americano, por mosquitos de hábitos estritamente silvestres, dos gêneros Haemagogus (H. janthinomys e H. albomaculatus) e Sabethes (S. chloropterus). As principais fontes de infecção são primatas não humanos, principais hospedeiros e amplificadores do vírus, particularmente macacos dos gêneros Allouata (macaco guariba), Cebus (macaco prego), Atelles e Callithrix. Outros mamíferos podem ser reservatórios como alguns marsupiais e roedores. Os seres humanos não imunes podem, acidentalmente, se infectar, penetrando em áreas enzoóticas. ${ }^{2}$

No ano de 1850, grande campanha implementada pelo governo imperial foi capaz de controlar a epidemia, e motivou a criação de uma comissão de engenheiros e uma junta de Higiene Pública que resultou em uma lei de defesa sanitária do país. Antes mesmo de se conhecer o agente etiológico e a forma de transmissão, as principais medidas de controle constavam de desinfecção de navios, isolamento, quarentena, medidas sanitárias coletivas, como aterramento de valas e limpeza de esgotos. ${ }^{3}$

Conseguiu-se o controle e a eliminação da doença em áreas urbanas, sendo os últimos casos registrados na cidade de Sena Madureira (AC), em 1942. Após esse período, o principal vetor urbano da febre amarela, Aedes aegypti, foi declarado erradicado do Brasil em 1958 pela Organização Mundial da Saúde, voltando a 
reinfestar nosso território a partir de 1976.4

A vigilância da febre amarela tem sido feita por meio da observação de primatas não humanos, como sentinelas da atividade do arbovírus. O desaparecimento da doença urbana não fez desaparecer o risco do retorno, uma vez que o vetor, o $A$. aegypti, poderia retornar em qualquer ponto do país. Até 1999, a vigilância da febre amarela era pautada no achado de casos humanos suspeitos, mas a partir daquela data, a observação de mortes de macacos em municípios de Tocantins e Goiás precedendo o surgimento de casos humanos, passou a sinalizar eventual risco de febre amarela humana. A circulação do vírus em populações de primatas não humanos (PNH) e consequente morte dos animais (epizootia) é definida como evento sentinela, e define medidas de intensificação de vacinação nos moradores das regiões afetadas. ${ }^{5}$

Atualmente O Ministério da Saúde atualizou no dia 07/02/2018 (Informe técnico 001/2018) as informações repassadas pelas secretarias estaduais de saúde sobre a situação da febre amarela no país. No período de monitoramento (de $1^{\circ}$ de julho/2017 a 6 de fevereiro de 2018), foram confirmados 353 casos de febre amarela no país, sendo que 98 vieram a óbito. Ao todo, foram notificados 1.286 casos de febre amarela suspeitos, sendo que 510 foram descartados e 423 permanecem em investigação, neste período. (M.S. 2018)

Cabe destacar que entre julho de 2016 à fevereiro de 2017, eram 509 casos de febre amarela confirmados e 159 óbitos confirmados. Os informes de febre amarela seguem, desde o ano passado, a sazonalidade da doença, que acontece, em sua maioria, no verão.

Segundo dados do Ministério da Saúde, a região Sudeste registrou 764 casos confirmados, a maior parte. A vacinação foi reforçada com 27,8 milhões de doses extras em cinco estados: Minas Gerais, Rio de Janeiro, São Paulo, Espírito Santo e Bahia. Em São Paulo, 44 municípios passaram a ser áreas com recomendação permanente. $^{5}$

O surto de febre amarela no Brasil, apesar de atingir regiões próximas de zonas urbanas de estados como Rio de Janeiro e São Paulo, foi classificado como silvestre pelo governo brasileiro.

\section{Febre Amarela no período Colonial em Vassouras}

Nos anos 1870, a febre amarela havia se transformado no problema de saúde pública do Império brasileiro, uma vez que o aspecto crucial estava na associação entre febre amarela e imigração. Com isso, a defesa da ideia de aclimatamento tornou-se a posição "oficial" do governo imperial. ${ }^{6}$

O debate entre os médicos ficava entre importação e contágio, ou miasmas e infecção. Porém havia consensos com relação ao flagelo ter sido novamente importado para a Corte e do que seria necessário fazer: um ataque total aos elementos causadores de infecção existentes no interior da cidade, isto é, as fontes produtoras das temidas "emanações miasmáticas". A febre amarela vitimava os indivíduos que não tinham "certo grau de aclimatação indispensável"; atacava impiedosamente "os estrangeiros recém-chegados e os brasileiros vindos do interior", mas era "quase nula sua influência nos pretos". Como consequência tinhase a diminuição das transações mercantis e, ainda mais grave, espantava os imigrantes, que seriam os braços para a agricultura e a indústria. ${ }^{6}$

O primeiro caso de febre amarela na cidade apareceu no dia 03 de abril de 1880, em junho diminuiu muito de intensidade, foi dada por extinta em julho, mas continuou a fazer algumas poucas vítimas até início do mês de outubro. Os primeiros casos se deram na rua Formosa (atual Caetano Furquim), onde se encontravam, segundo o comissário do governo, os principais focos de infecção, citados mais a frente quando da volta da enfermidade. Quanto ao número de infectados e de casos fatais, houveram duas estatísticas feitas: uma comunicada pelo delegado (de Vassouras) da Junta Central de Higiene Pública, o Dr. Lucindo Pereira dos Passos Filho, em 10 de junho de 1880, ao Barão do Lavradio, e outra, mais detalhada, foi organizada pelo farmacêutico Falcão, representada na tabela 1 e no quadro 1.

Quanto às estratégias de intervenção sobre a existência coletiva em nome da vida, percebe-se que houve certa resistência na execução pela municipalidade e um controle, ou uma vigilância, mais próximo do que se pensava por parte do governo do império. Como que a febre amarela ia fazendo suas vítimas na cidade, o próprio presidente da Junta Central de Higiene, profere palavra dura com relação a uma cidade que se propunha ser uma "miniatura londrina dos trópicos" e assim se percebe com mais clareza a "intervenção do governo federal".

De acordo com o Jornal "O Vassourense", em uma matéria publicada em 26 de março de 1882, em que destaca-se um trecho a seguir:

Tendo encontrado a cidade de Vassouras em péssimas condições higiênicas, pelo abandono em que a deixou a sua atual municipalidade, como se pôde ver no oficio dirigido em 13 de Março ao Exm. Sr. Ministro do Império (...), e vendo que não eram atendidas as medidas sugeridas pelos meus ilustrados colegas, os clínicos de Vassouras, os quais contra isto protestarão pela imprensa, resolvemos propor as seguintes medidas à comissão de saneamento nomeada pelo Sr. Ministro do Império, devendo desde já acrescentar que, por culpável incúria de alguém, elas ou não foram executadas, ou o foram de um modo incompleto e tardio.

Essas propostas de intervenção sobre a existência coletiva: na Corte prevalecia na forma de toda uma 
Quadro 1. Dados das estatísticas feitas pelo farmacêutico Falcão, citada pelo Comissário do Governo no Jornal O Vassourense, 19 de fevereiro de 1982, ano I, nº 1, p.2.

\begin{tabular}{|l|r|r|}
\hline \multicolumn{1}{|c|}{ Idade } & Infectados & \multicolumn{2}{|c|}{ Vítimas Fatais } \\
\hline Menores de 10 anos & 12 & 5 \\
\hline 11 a 20 anos & 27 & 11 \\
\hline 21 a 30 anos & 22 & 6 \\
\hline 31 a 40 anos & 20 & 6 \\
\hline Mais de 40 anos & 18 & 4 \\
\hline
\end{tabular}

Fonte: Jornal O Vassourense, 1982.

Figura 1. Gráfico referente a estatística do farmacêutico Falcão acima representado em tabela.

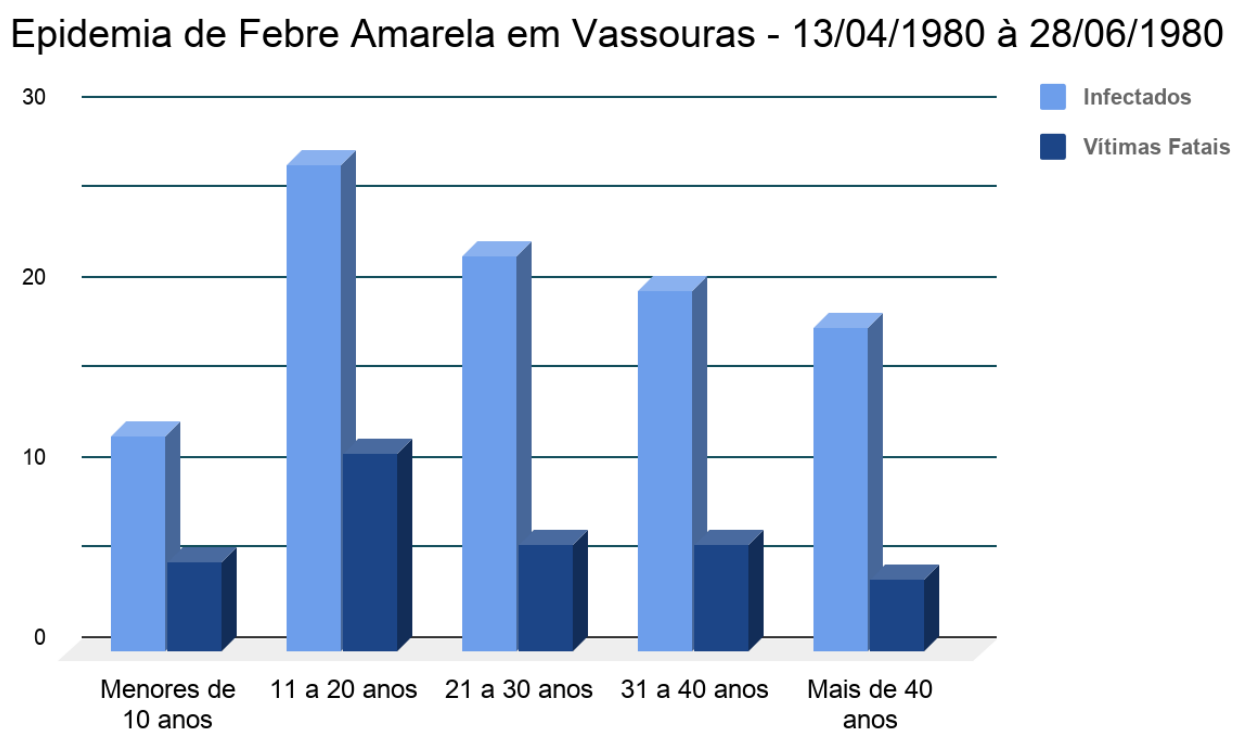

Fonte: Jornal O Vassourense, 1982

imposição sobre a população, alcançando resistências e acarretando violência, a forma como estas foram propostas, para a cidade de Vassouras, em nada diferiram, pois em todo tempo se observam os imperativos: impedir, proibir, obrigar. E quanto à aplicação, nem todas se realizaram ou o foram tardiamente, como também ocorria na Corte, porém sem resistências por parte da população.

Os doentes foram atendidos na Casa de Misericórdia da cidade, na enfermaria aberta pelo governo federal, porém o mais recomendável foi que os doentes fossem tratados em suas residências, onde eram visitados pelo comissário do governo. Entre infectados e casos fatais pela febre amarela de janeiro a maio de 1881, somam-se 475, dos 81 casos fatais: 56 foram homens e 25 mulheres; e suas nacionalidades, eram: 57 brasileiros, 12 portugueses, 10 italianos e 2 africanos.

Tendo assim a epidemia de febre amarela em 1881, o primeiro diagnóstico de infecção em 6 de Janeiro e em 25 de maio o último, no dia 31 de maio o Dr. José Maria Teixeira, comissário enviado pelo governo provincial dá por encerrada sua comissão. E por fim, percebe-se a partir: da decisão proferida pelo juiz de direito da cidade - apoiado pela população - de 
mandar aterrar as covas da parte inferior do cemitério municipal (Jornal O Vassourense, 26 de março de 1882); do discurso do próprio jornal "O Vassourense" nove meses depois de dada como finda a epidemia - ao se referir a esta, se refere como febre amarela a partir do juízo proferido pelo comissário, reivindicando a aplicação de medidas indicadas por esse e denunciando irregularidades, que assim se constituíam baseadas no discurso desta autoridade (Jornal O Vassourense, 19 de março de 1882) e da Câmara Municipal - ainda que tardiamente - aplicando essas orientações (Jornal O Vassourense, 28 de maio de 1882), como a sociedade vassourense subjetivou esse discurso de verdade, nos quais os indivíduos foram levados a atuar sobre si próprios, sob certas formas de autoridade, em relação a estes discursos de verdade, em nome da vida ou da saúde individual ou coletiva.

\section{Febre Amarela em Vassouras em 2018}

Atualmente, foram notificados no Centro de Vigilância em Saúde, 5 (cinco) casos da doença no município e 3 (três) óbitos confirmados, em uma população de 35.768 habitantes. $^{7}$

A vigilância epidemiológica tem por objetivos manter erradicada a febre amarela urbana e controlar a silvestre. Todos os casos suspeitos da doença devem ser investigados, visando mapeamento das áreas de transmissão e identificação de populações de risco para prevenção e controle. Para isso, profissionais da área de saúde foram capacitados, tanto em vigilância específica da febre amarela como no manejo de primatas não humanos (macacos).

A meta de vacinação é atingir $100 \%$ da população em todos os municípios das regiões endêmicas, de transição e de risco potencial para a doença. E para isso, estimula estratégias diferenciadas: fora as salas de vacinação distribuídas por todo o território, a vacina é dada de casa em casa aos moradores de zonas rurais, postos são montados em escolas e existe uma mobilização social feita em conjunto com o Programa Saúde da Família (PSF).

Na Estratégia Saúde da Família Dr José F. de Souza, que atende os bairros onde foram realizadas a varredura, sendo eles o Matadouro e Conjunto Habitacional, estão cadastradas 3.382 (três mil, trezentos e oitenta e dois) pessoas.

Das notificações de casos confirmados por febre amarela, nenhum indivíduo desta área foi infectado.

\section{Vacinação}

A forma mais eficaz de evitar a febre amarela é por meio da vacinação. A vacina contra febre amarela elaborada com vírus vivo atenuado cepa 17DD é segura e eficaz a partir dos 9 meses de idade em residentes e viajantes para áreas endêmicas, e a partir dos 6 meses em situações de surto. O nível de anticorpos será adequado para proteção após 10 dias da sua aplicação, mas somente na primeira aplicação, não sendo necessário aguardar esse período na dose de reforço.

De acordo com dados do Governo, Ministério da Saúde e Fiocruz, os estudos mostraram que a proteção da dose fracionada, de $0,1 \mathrm{ml}$, é a mesma da dose

Em Vassouras, as doses das vacinas foram padrão, sendo $0,5 \mathrm{ml}$ aplicadas em braço esquerdo, subcutânea e região deltoide.

\section{Contra indicações para imunização}

-Crianças menores de 9 meses de idade.

-Pacientes com imunodepressão de qualquer natureza. -Pacientes infectados pelo HIV com imunossupressão grave, com a contagem de células CD4 $<200$ células/ $\mathrm{mm} 3$ ou menor de $15 \%$ do total de linfócitos para crianças menores de 6 anos.

-Pacientes em tratamento com drogas imunossupressoras (corticosteroides, quimioterapia, radioterapia, imunomoduladores).

-Pacientes submetidos a transplante de órgãos. Pacientes com imunodeficiência primária.

-Pacientes com neoplasia.

-Pacientes com história pregressa de doenças do timo (miastenia gravis, timoma, casos de ausência de timo ou remoção cirúrgica).

-Indivíduos com história de reação anafilática relacionada a substâncias presentes na vacina (ovo de galinha e seus derivados, gelatina bovina ou outras)

\section{Notificação}

A doença é de notificação compulsória e imediata, portanto todo caso suspeito deve ser prontamente comunicado por telefone, fax ou e-mail às autoridades (centros de vigilância epidemiológica das secretarias de saúde dos estados e municípios), por se tratar de doença grave com risco de dispersão para outras áreas do território nacional e mesmo internacional. ${ }^{10,11}$ A notificação deve ser registrada por meio do preenchimento da Ficha de Investigação de Febre Amarela, do Sistema de Informação de Agravos de Notificação (Sinan). ${ }^{12}$

\section{A Estratégia de Varredura e Monitoramento Vacinal realizada}

Na Estratégia Saúde da Família Dr José F. de Souza, que atende os bairros onde foram realizadas 
Quadro 2. Orientações para vacinação dose Padrão $0.5 \mathrm{ml}$

\begin{tabular}{|c|c|}
\hline Situações & Orientações \\
\hline $\begin{array}{l}\text { Criança com } 9 \text { meses a menores de } 2 \text { anos de idade, não } \\
\text { vacinada. }\end{array}$ & Administrar uma dose. \\
\hline $\begin{array}{l}\text { Gestante não vacinada, residentes em área COM } \\
\text { transmissão ativa da febre amarela. }\end{array}$ & Administrar uma dose. \\
\hline $\begin{array}{l}\text { Viajante internacional que necessite a emissão do } \\
\text { Certificado Internacional de Vacinação e Profilaxia (CIVP), } \\
\text { não vacinado }\end{array}$ & $\begin{array}{l}\text { Administrar uma dose, pelo menos } 10 \text { dias antes da viagem. } \\
\text { Atenção: alguns países só aceitam a vacinação com pelo } \\
\text { menos } 10 \text { dias antes da viagem, mesmo com a emissão do } \\
\text { CIVP anterior a esse prazo. }\end{array}$ \\
\hline $\begin{array}{l}\text { Mulher não vacinada, que estiver amamentando criança } \\
\text { maior de } 6 \text { meses de idade. }\end{array}$ & Administrar uma dose. Realizar recomendações específicas \\
\hline $\begin{array}{l}\text { Pessoas acima de } 60 \text { anos de idade que não apresentem as } \\
\text { condições clínicas especiais ou contraindicações, não } \\
\text { vacinada. }\end{array}$ & $\begin{array}{l}\text { E fundamental a avaliação do serviço de saúde para } \\
\text { certificar o beneficio/risco da vacinação, levando em conta } \\
\text { os riscos da doença, comorbidades e eventos adversos nessa } \\
\text { faixa etária. } \\
\text { Dependendo da avaliação, administrar uma dose. }\end{array}$ \\
\hline
\end{tabular}

Fonte: Ministério da Saúde 2017 - Febre amarela - tabela readaptada

Figura 2.Gráfico construído a partir dedados colhidos no DATASUS a partir do Sistema de Informação do Programa Nacional de Imunizações, referente a USF José F. de Souza.

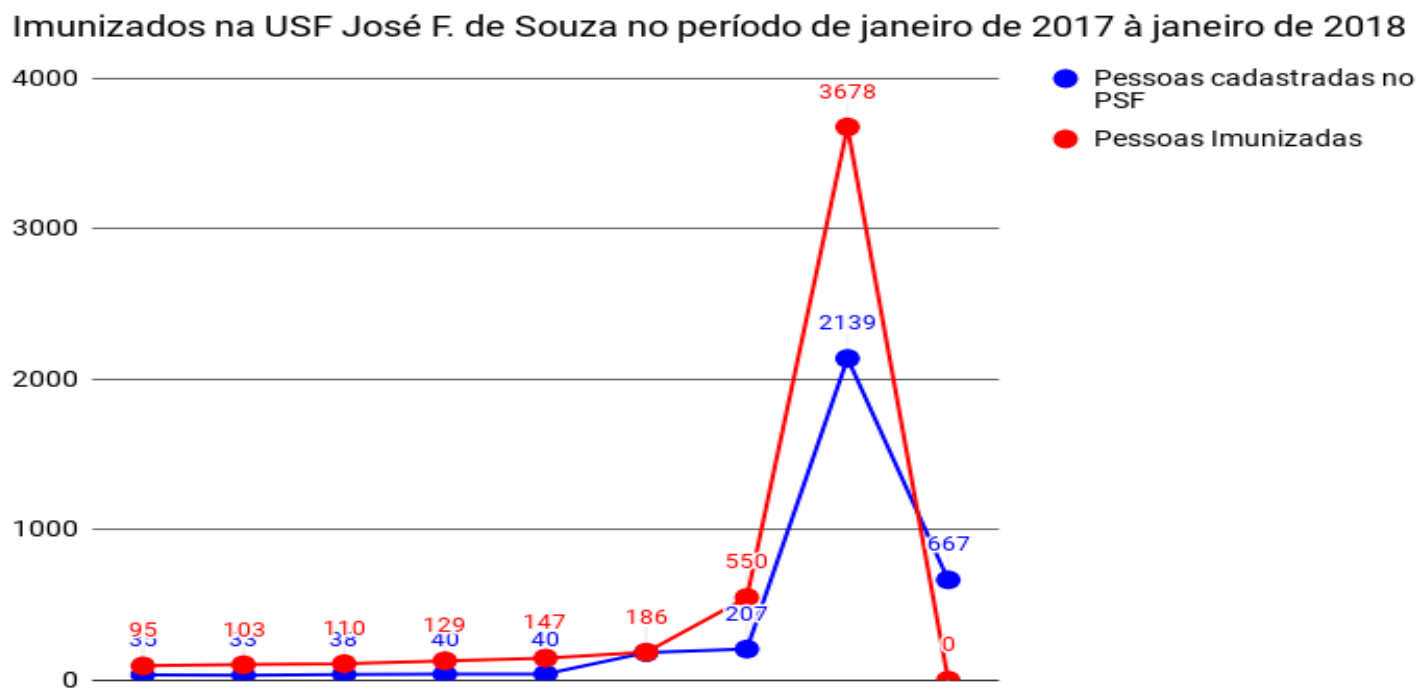


Quadro 3. Dados colhidos no DATASUS a partir do Sistema de Informação do Programa Nacional de Imunizações, referente a USF José F. de Souza.

\begin{tabular}{|c|c|c|}
\hline Idade & $\begin{array}{c}\text { Pessoas cadastradas USF } \\
\text { José F. de Souza }\end{array}$ & $\begin{array}{l}\text { Pessoas Vacinadas USF José F. de } \\
\text { Souza no período de janeiro de } 2017 \\
\text { à janeiro de } 2018\end{array}$ \\
\hline 9 Meses à 01 ano de idade & 35 & 95 \\
\hline 1 ano & 33 & 103 \\
\hline 2 anos & 38 & 110 \\
\hline 3 anos & 40 & 129 \\
\hline 4 anos & 40 & 147 \\
\hline 5 à 9 anos & 183 & 186 \\
\hline 10 à 14 anos & 207 & 550 \\
\hline 15 à 59 anos & 2.139 & 3.678 \\
\hline 60 e mais & 667 & 0 \\
\hline Total & 3.382 & 5.004 \\
\hline
\end{tabular}

Fonte: DATASUS, 2018.

a varredura, sendo eles o Matadouro e Conjunto Habitacional, estão cadastradas 3.382 (três mil, trezentos e oitenta e dois) pessoas.

De acordo com o Sistema de Informação do Programa Nacional de Imunizações (SI-PNI), foram imunizadas contra febre amarela no USF José F. de Souza, 3.522 (três mil quinhentos e vinte e duas) pessoas no ano de 2017. Em janeiro de 2018, último registro do SI-PNI, foram imunizadas 1.482 (mil quatrocentos e oitenta e duas) pessoas contra a febre amarela, totalizando 5.004 indivíduos imunizados nesta unidade. Estes dados estão descritos na figura 2 e no quadro 3.

É possível verificar que a cobertura vacinal é de aproximadamente $176 \%$. O número da população flutuante imunizada deste território é de 1.622 indivíduos.

Durante a varredura de cobertura vacinal contra a febre amarela nos bairros Matadouro e Conjunto Habitacional, efetuamos o levantamento dos seguintes dados: Indivíduos que já haviam sido imunizados, indivíduos imunizados durante a varredura, indivíduos não vacinados durante a varredura, total de famílias e pessoas atendidas. Estes dados estão demonstrados nas figuras 3 e 4 .

Os indivíduos que foram vacinados durante a varredura, ao serem indagados por que não haviam sido imunizados, alegaram falta de tempo e outros por receio dos efeitos colaterais. Os indivíduos não imunizados, não foram vacinados durante a varredura por alguma apresentação clínica e contra indicação para vacina.

O Sistema de Informação do Programa Nacional de Imunização-SI-PNI do qual foram retirados o número de imunizados, propicia acompanhamento dos resultados das ações de vacinação junto a sociedade buscando a partir dos resultados, a conduta ideal a ser tomada. Sendo fundamental que o sistema de informação utilizado seja confiável para o auxílio nas análises em 
Figura 3. Gráfico com dados da Varredura vacinal no bairro Conjunto Habitacional. Fevereiro de 2018

\section{Bairro Conjunto Habitacional}

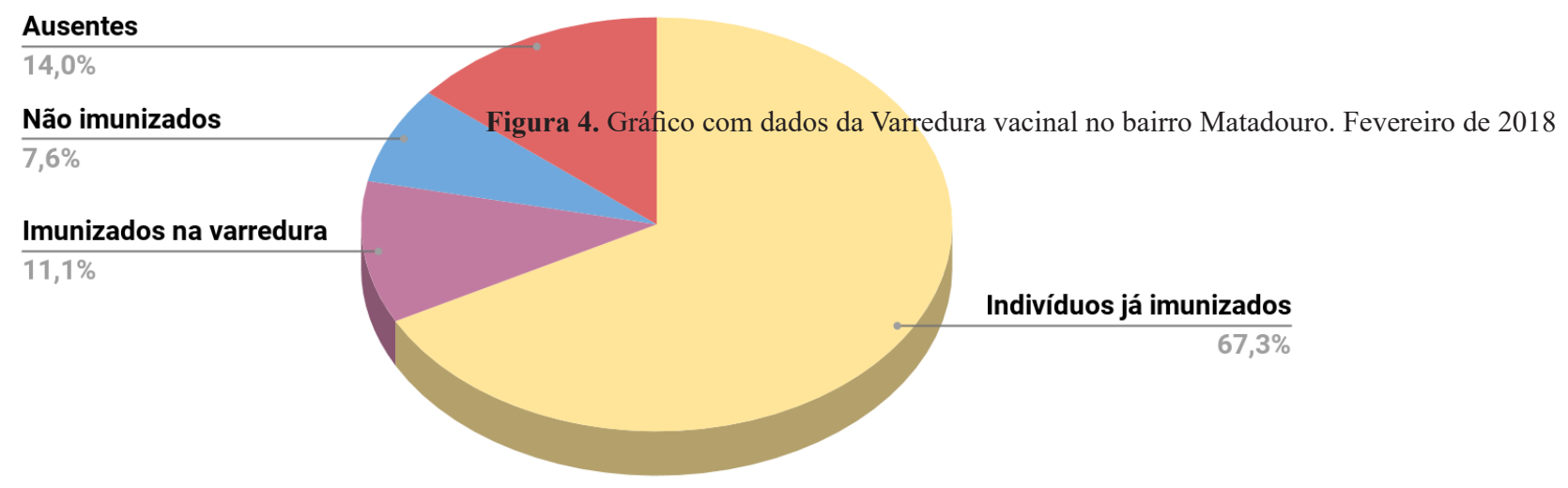

Fonte: Dados do Pesquisador, 2018.

Figura 4. Gráfico com dados da Varredura vacinal no bairro Matadouro. Fevereiro de 2018

\section{Bairro Matadouro}

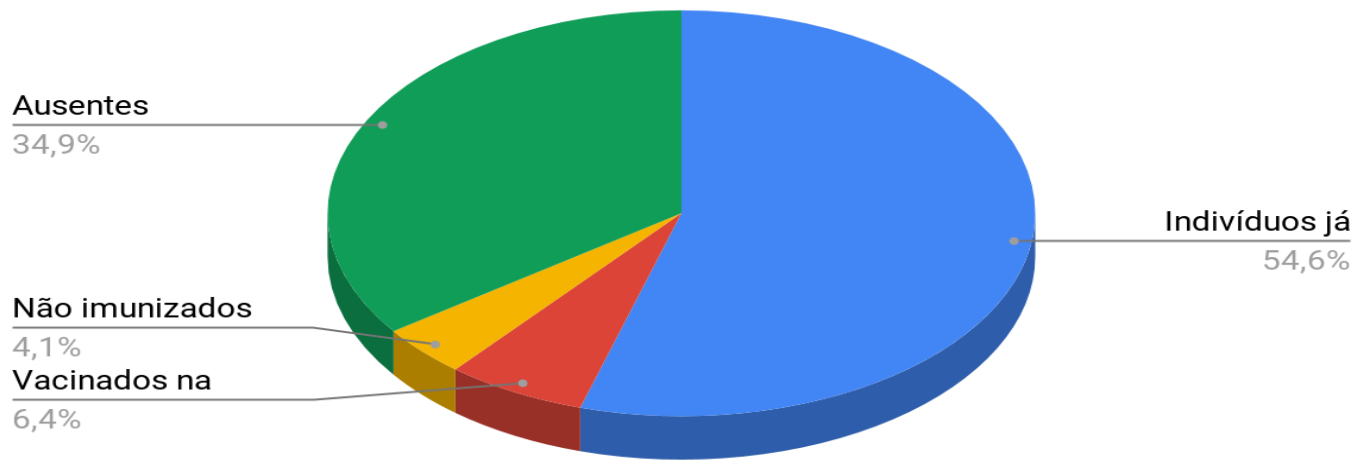

Fonte: Dados do Pesquisador, 2018.

saúde e planejamento, monitoramento e avaliação dos dados, possibilidade de análise histórica e a conversão em informação para o planejamento das ações de saúde pública.

A partir dos dados apresentados, foi possível perceber que a cobertura vacinal exposta na figura 2 , no período de janeiro de 2017 à janeiro de 2018 foi de aproximadamente $176 \%$ nesta micro área, por causa da população flutuante. Porém durante a varredura, ainda assim encontramos indivíduos que não haviam sido vacinados.

Com a cobertura vacinal atingindo $100 \%$, acaba se entendendo que esta população está fora dos riscos acerca da doença, porém a partir da varredura podemos que ainda haviam indivíduos não vacinados, trazendo repercussões negativas tanto nos aspectos de prevenção como de promoção da saúde da população.

\section{Considerações Finais}

O alcance dos objetivos nos permitiu verificar a importância da varredura e monitoramento vacinal, o atendimento pelas equipes de vacinação que promovam a qualidade dos serviços prestados, o acolhimento e a adesão da população. Levando em consideração as dificuldades encontradas nas unidades de saúde, onde 
percebe-se grande número de tarefas designadas e carência de profissionais, vale ressaltar que é de suma importância o monitoramento vacinal, sendo maior ainda frente a uma epidemia de febre amarela.

\section{Referências}

1. Brasil. Ministério da Saúde. Agência de Saúde - Ministério da Saúde atualiza casos de Febre Amarela - 16 de janeiro de 2018. Disponível em: http://portalms.saude.gov.br/noticias/agencia-saude/42327-ministerio-dasaude-atualiza-casos-de-febre-amarela-2 acessado em 17/03 às 20:00hs.

2. Brasil. Ministério da Saúde. Histórico Febre Amarela. 2018. Disponível em http://bvsms.saude.gov.br/bvs/febreamarela/historico.php acessado 17:03 às 18:30hs.

3. Teixeira, AO. A Epidemia de Febre Amarela na cidade de Vassouras, 1880-1881. XIV Encontro Regional de ANPUH-RIO-Memória e Patrimônio, Associação Nacional de História, RJ, Anais, ISBN 9788560979080: 1-10. Disponível em http://www.encontro2010.rj.anpuh.org/resources/ anais/8/1276742283 ARQUIVO FebreAmarelaemVassouras, 1880-1881. pdf. Acessado em 23/03/2018 ás $19 \overline{\mathrm{h} s}$.

4. Brasil. Ministério da Saúde. Secretaria de Vigilância em Saúde. COES - Febre Amarela. Centro de Operações de Emergências em Saúde Pública sobre Febre Amarela. Informe - No 13/2017. Brasília. 2017.

5. Brasil. Ministério da Saúde. Secretaria de vigilância em Saúde. Departamento de Vigilância em Saúde. Orientaçoes para profissionais de saúde sobre febre amarela silvestre. Nota informativa $n^{\circ} 02 / 2017$. Informa a situação epidemiológica da Febre Amarela e as recomendações para intensificação da vigilância no Brasil. Ministério da Saúde, 201.

6. Brasil. Ministério da Saúde. Secretaria de Vigilância em Saúde. Departamento de Vigilância das Doenças Transmissíveis. NOTA INFORMATIVA No 02/2017. Brasília. 2017.

7. IBGE disponível em https:/cidades.ibge.gov.br/brasil/rj/vassouras/ panorama, 25 de fevereiro de 2018, ás 20:30h.

8. Jornal O Vassourense, 19 de fevereiro de 1882 , ano $\mathrm{I}, \mathrm{n}^{\circ} 1$. , 26 de fevereiro de 1882 , ano $I, n^{\circ} 2$.

9. Brasil. Ministério da Saúde. Histórico Febre Amarela. disponível em http://bvsms.saude.gov.br/bvs/febreamarela/historico.php acessado 17:03 às 18:30hs.

10. Brasil. Ministério da Saúde. Agência de Saúde - Ministério da Saúde atualiza casos de Febre Amarela - 16 de janeiro de 2018. Disponível em http://portalms.saude.gov.br/noticias/agencia-saude/42327-ministerio-dasaude-atualiza-casos-de-febre-amarela-2 acessado em 17/03 às 20:00hs.

11. Petrucelli, José Luís. Café escravidão e meio ambiente: O declínio de Vassouras na virada do século XX. Estudos Sociedade e Agricultura, Rio de Janeiro: UFRRJ, mai. 1994.

12. Brasil. Ministério da Saúde. Governo Federal. Disponível em: http:// www.brasil.gov.br/saude/2018/01/entenda-de-uma-vez-o-que-e-a-dosefracionada-da-vacina-contra-febre-amarela Acessado em 19/03 às 21:30hs 